\title{
Identification and mapping of early thermoacoustic phenomena in gas turbine test rig
}

\author{
by C. Allouis*, A. Ferrante ${ }^{\star \star}$ and G. Molfetta** \\ * Istituto di Ricerche sulla Combustione - CNR, Napoli-Italy, allouis@irc.cnr.it \\ ${ }^{* *}$ Centro Combustione Ambiente srl, Gioia del Colle - Italy, Antonio.Ferrante@ansaldoboiler.it
}

\begin{abstract}
In this paper, an optical approach is tested to spatially characterize combustion fluctuations in a single burner atmospheric gas turbine test rig. The target of present investigation was to test two different techniques with the aim to characterize the thermoacoustic behavior of burners during combustion tests campaign. The analysis based on fast infrared imaging of flames, coupled with dynamic pressure transducers and photomultiplier measurements, has been elaborated on a $3 \mathrm{MW}$ gas turbine test rig equipped with full scale burner tested in atmospheric conditions. The rig has been purposely designed to be tuned on acoustic frequencies detected in real gas turbine machine equipped with 24 burners and operating at 20 bar. In atmospheric test campaign the burner evidenced main oscillations at low frequencies around $82 \mathrm{~Hz}$ and $146 \mathrm{~Hz}$. These frequencies have been recorded in real machine too. The technique allowed identifying these frequencies in the 2D dimensions under humming conditions. The developed tool has enabled to design a methodology for comparing different burners operating in different conditions from thermoacoustic point of view.
\end{abstract}

\section{Introduction}

The development of new technology for power and propulsion will require a better control on polluting compounds emitted from combustion sources. Fuel injection and depletion processes notably influence the formation of the pollutants in the combustion chamber and consequently their emissions. Many researches are focused on new concepts for ultra-low $\mathrm{NO}_{x}$ burners, with developments in fuel preparation and wall cooling techniques in the case of gas turbine combustors. Concerning Gas Turbine a mature technological solution for the reduction of pollution, while increasing the specific power, is the use of lean mixtures premixed before fuel/air enter into the combustion chamber.

Nevertheless, these technologies are affected by many problems that must be solved in order to make them more reliable. Numerous experimental studies and numerical models were developed to understand the behaviour of burners in gas turbines; in particular there are current researches to understand fuel/air interaction in the premixing duct, upstream of the combustion chamber [1-4]. Indeed, the characterization of the fuel mixing with air is very important for the optimization and the choice of the injection technology, which is important since it influences the homogeneity of the fuel/air mixture. Unfortunately, developments in premixed combustion are generally accompanied by increase in occurrence of oscillating combustion [5-6]. Unstable combustion refers to self-sustained combustion oscillations at or near the acoustic frequency of the combustion chamber, which are the result of the closed-loop coupling between unsteady heat release and pressure fluctuations. The heat release fluctuations produce pressure fluctuations and it is well known and well understood; however, the mechanisms whereby pressure fluctuations result in a heat release fluctuations are not. Rayleigh [7] postulated that, for the pressure oscillations to be amplified, the heat release and pressure fluctuations must be in phase. The exact mechanism of unstable combustion is not yet completely understood.

Moreover, in order to validate the different numerical models of combustion instabilities, real time measurements are needed giving thus the possibility of a better description of the phenomena. Acoustic frequencies can be easily measured by fast traducers, while the oscillations of the equivalence ratio can be obtain performing real time measurements [8]. Other time averaged techniques (LIF, PLIF, Chemiluminescence, etc.) give an idea of the combustion process [8]. Usually, UV-Visible spectroscopy is used to obtain information on the flame structures. New available technology as Fast InfraRed Imaging (FAIRI) allows instabilities investigation in the 2-dimensions [9-10]. The objective of this paper is to test the capability of this technique based on fast infrared imaging in individuating the flame and fluid dynamic fluctuations and the eventual correlations between them. To do that, real time measurements were performed on a $3 \mathrm{MW}_{\text {th }}$ test rig combining FAIRI, pressure fluctuation and flame front tracer analyses. 
http://dx.doi.org/10.21611/qirt.2014.024

\section{Experimental Set-up}

Measurements have been performed on $3 \mathrm{MW}_{\text {th }}$ test rig: it permits to carry out investigation on flame instability on full scale prototype gas turbine burner at nearly atmospheric condition. The test rig consists of a plenum chamber upstream of a swirl inducing burner and a combustion camber downstream of the burner. The circular cross section combustion chamber consists of a ceramic flame tube adherent to a metallic water cooled liner. Combustion air is supplied by a blower and heated by an electrical heater able to increase air temperature to $450^{\circ} \mathrm{C}$.

Prototype burner is composed by two stabilizing air swirlers and three gas injectors: a diffusion nozzle and two premixed systems; the diffusion nozzle behaves like a high stability pilot for premixed unstable flame.

During the tests performed for the present investigation, prototype burner has been always fed by the main premixed line and in the first step using the diffusion line and in the following step using the second premixed line. This caused a variation in flame structure and dynamic.

The combustion chamber is equipped with several optical and/or sampling accesses along the external surface and an optic window on the bottom of flame tube: this window permits a high quality vision of burner. During the test campaign the sideward accesses have been used to install flush mounted piezo electric microphones by means of water cooled probes (Fig.1). For reason of confidentiality regarding the industrial process, no more detailed figure is presented about the experimental set-up.

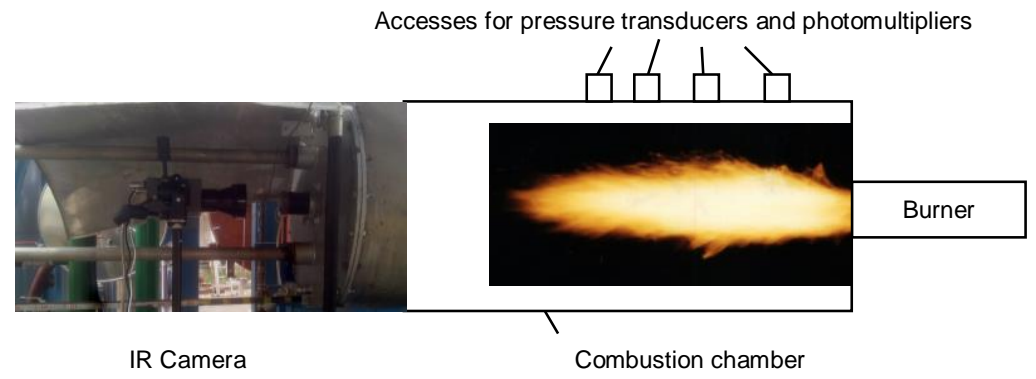

Fig.1. Sketch of the experimental Set-up

One of those accesses has been used to install an optic detection system composed by a photomultiplier, an interferential filter and a focusing lenses element. The filter is centered at $430 \pm 10 \mathrm{~nm}$. This wavelength represents the specific chemiluminescence of $\mathrm{CH}^{\star}$ radical. Many investigations on steady flames have shown that in first approximation the global heat-release rate is proportional to the global spontaneous emission of $\mathrm{CH}^{*}$ radicals [11-12]. Therefore natural $\mathrm{CH}^{\star}$ emission produced by burner flame has been measured by means of the photomultiplier equipped with a $10 \mathrm{~nm}$ narrowband $\mathrm{CH}^{\star}$ filter. The electrical current from photomultiplier tube is converted to a voltage by a low noise amplifier for signal processing. The amplifier feedback resistance allows a current-to-voltage conversion factor of $1 \mathrm{~V} / \mu \mathrm{A}$, and covers a frequency bandwidth from DC to $20 \mathrm{kHz}$. The voltage signal from phototube is sampled at $4096 \mathrm{~Hz}$ by means of a National Instruments $\mathrm{CDAQ}{ }^{\circledR}$ acquisition system.

Data flow is managed by customized software developed by using National Instruments Labview ${ }^{\circledR}$ : this software among other tasks, performs FFT calculation of phototube module signal and display the persistence of spectra frequencies in an on line graph, figure 2. This kind of graph has been very useful during tests campaign to mark thermoacoustic frequencies emerging from the noise background, without taking into account relatives amplitudes.

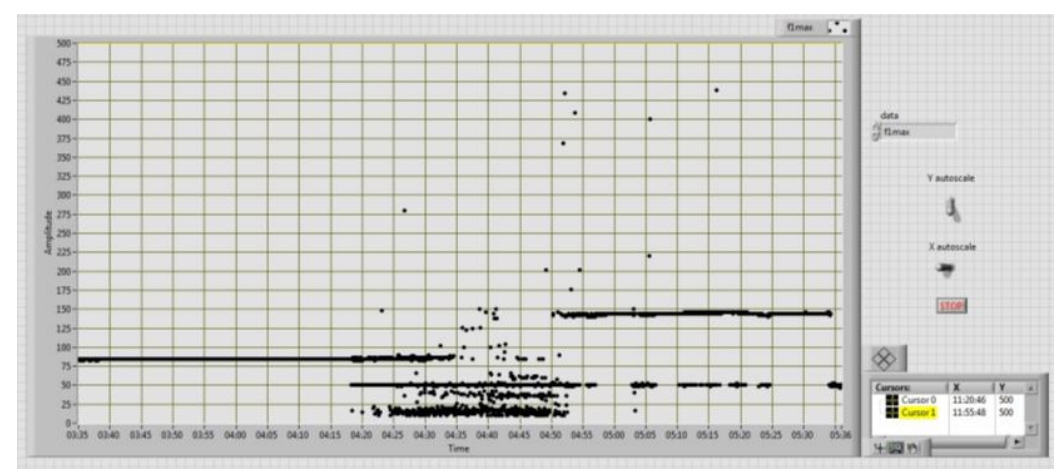

Fig.2. typical graph obtained from the $\mathrm{CH}^{*}$ chemiluminescence analysis. 
The graph shows the persistence of two components at 82 and $146 \mathrm{~Hz}$, in addition to $50 \mathrm{~Hz}$ supply net frequency; the two frequencies occurred at the two feeding modes of the burner.

Fast IR imaging was performed simultaneously using a Phoenix Camera from FLIR Systems with a InSb sensor matrix of 320x256 pixels and a sensitivity ranged between 1.5 and $5 \mu \mathrm{m}$. The films were acquired at $1 \mathrm{kHz}$ with a sized windows of $224 \times 110$ pixels. Data were transferred to the Data Transfer System by mean of a Camera link@ cable. The FLIR Data Transfer System was able to grab up to $40 \mathrm{Mbytes} / \mathrm{s}$. The integration time of the sensor was optimized to obtain a signal-to-noise ratio greater than four. A $100 \mathrm{~mm}$ lens (f:2.3, Si:Ge) was used and focused at a distance of $2.5 \mathrm{~m}$ from the camera, namely $1.5 \mathrm{~m}$ far from the burner throat. A neutral density for the whole band was used to reduce the flame intensity during the acquisition. A sapphire window is used on the combustor access.

Images were analyzed by the RTools software and Labview ${ }^{\circledR}$. The Fast Fourier Transformation was performed on different selected Region Of Interest of the burner.

\section{Results and Discussion}

IR Imaging was performed together with fast recording of both pressure transducers and $\mathrm{CH}^{\star}$ chemiluminescence. The IR acquisition speed was set up at $600 \mathrm{~Hz}$ with a window of $214 \times 184$ pixels. The three investigated positions from IR imaging are presented in figure 3 by the black and white circles. These positions were chosen in base of the possible influence of the fluid dynamic parameters on the combustion process [10].

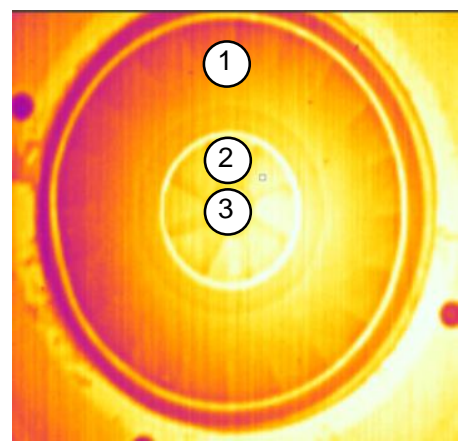

Fig.3. Position of investigated positions by IR image analysis of the burner

The investigations had two objectives: one to compare transducer and $\mathrm{CH}^{*}$ results with those obtained with IR imaging analysis and to confirm the trend observed in ref [10]; and on another hand to localize spatially the humming phenomenon during the combustion providing thus a good tool for the optimization of the burner design.

A Region Of Interest (ROI) window with a fixed size of $3 \times 3$ pixels was moved inside the three investigated regions. The Fast Fourier Transformation of the maximum of the intensity in the ROI was performed. These FFT analyses gave an averaged idea of the distribution of the frequencies of the combustor. These analyses were performed under normal operating and under Humming conditions. Typical spectra are presented in figure 4. Humming conditions were created by the operator changing the air fuel ration in the burner. Experiments were time limited in order to avoid any damage of the device. 


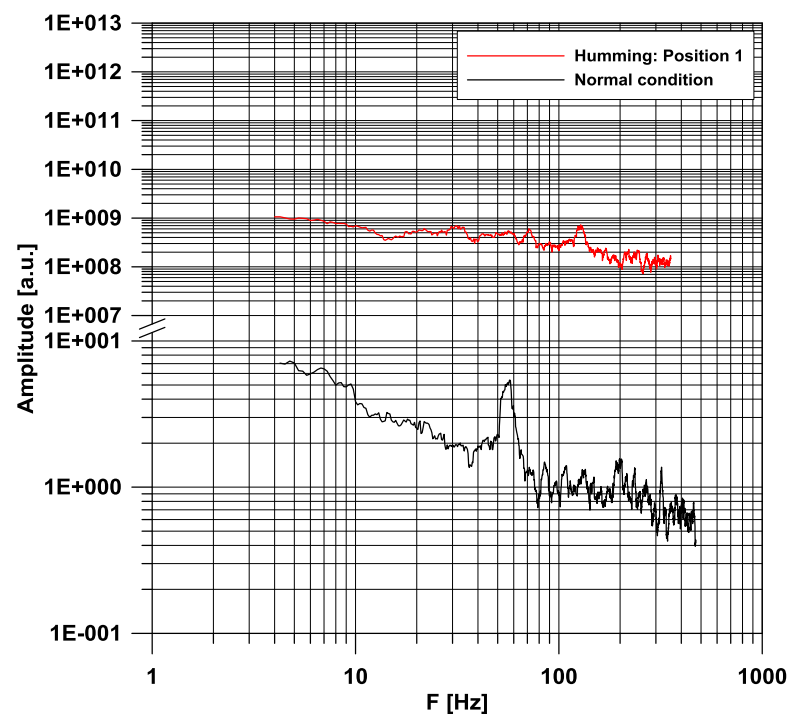

Fig.4. Frequency analysis of IR images under normal and humming conditions.

We observed than flame intensity, represented by the signal intensity background, is low under normal condition, while humming generates more intense flames. A typical frequency is found at around 50-60 Hz under normal combustion, while humming generates frequency around $140 \mathrm{~Hz}$. Moreover, the humming phenomenon was confirmed by fast transducers and photomultiplier records analysis presented in Figure 5 . We clearly observed two trends of the frequencies: one for high frequency $(\sim 140 \mathrm{~Hz})$ and another one at low frequency $(\sim 10 \mathrm{~Hz})$.

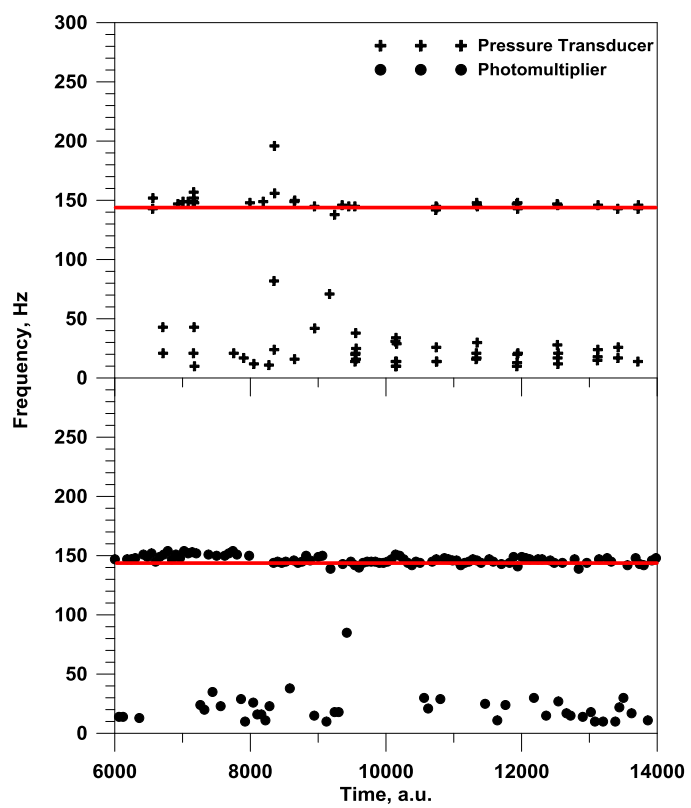

Fig.5. Frequency analysis of pressure transducer and photomultiplier under humming conditions.

We can notice the good agreement between the transducer and the photomultiplier results. This indicates a cross correlation between the acoustic pressure and the combustion. Even though the phenomenon is well known, the mechanisms that lead to "humming" are not clearly explained so far [13]. Another important point regards the correlation between the IR results and the other measuring techniques. A similar approach was used in the past by Blevins et al. [14] trying to correlate $\mathrm{CH}^{*}$ chemiluminescence signals to temperature measurements. These tests were performed using a cooled InSb sensor in a partially premixed flame, but in this case the sensor was used to calibrate a thin thermocouple. In our experiments we used directly a IR camera based on the same kind of sensor (InSb). In that case, 
we did not measure the temperature but the Irradiance of the flame. The good agreement allows to locate spatially the "humming" phenomenon and to obtain a qualitative map the its intensity in the focused plane. The results are presented in figure 6 in term of normalized intensity. The intensity is normalized to its maximum. We observe that the maximum is located on the outer left side of the burner, while less intense phenomenon is distributed around the outer ring. Minor intensity are found at the center of the burner. These results are very important for the burner designer for the optimization of the combustion lowering the emissions.

Further investigation should be performed to deeply understand which spectral band is involved and is strictly correlated to the $\mathrm{CH}^{*}$ radical emission.

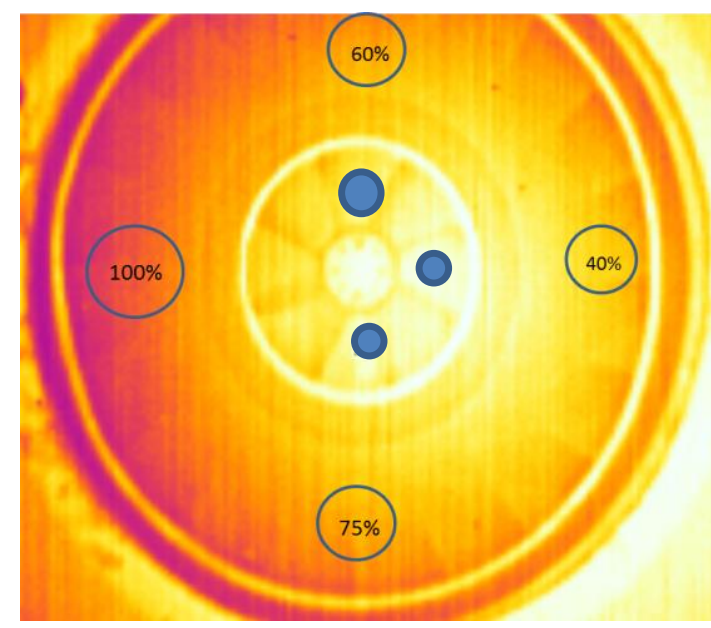

Fig.5. Identification map of the "humming" phenomenon.

\section{Final Remarks}

An industrial burner under unstable combustion conditions has been studied by mean of acoustic pressure analysis, $\mathrm{CH}^{*}$ chemiluminescence emission measurements and Fast IR Imaging. The results of all the techniques present a good correlation about the frequency analysis of the combustion instabilities. Moreover, the use of the IR imaging abled to map these instabilities respect to the burner design and came out as a helpful tool for the burner design and for the development of a methodology for comparing different burners operating in different conditions from thermoacoustic point of view

\section{REFERENCES}

[1]. Cowell L. H. and Smith K. O., "Development of a Liquid-Fueled, Lean-Premixed Gas Turbine Combustor", Journal of Engineering for Gas Turbines and Power, vol. 115, p 554, 1993.

[2]. Gradinger T. B., Inauen A., Bombach R., Kappeli B., Hubschmid W., Boulouchos K., "Liquid-fuel/air premixing in gas turbine combustors: experiment and numerical simulation”, Combustion and Flame, vol. 124:3, pp 422-443, 2001.

[3]. Brandt M., Rachner M., Schmitz G., "An Experimental and Numerical Study of Kerosene Spray Evaporation in a Premix Duct for Gas Turbine Combustors at High Pressure”, Combustion Science and Technology, vol. 138, p 313, 1998.

[4]. Snyder T. S., Rosfjord T.J., McVey J.B., Hu A.S., Schlein B.C., "Emission and Performance of a Lean-Premixed Gas Fuel Injection System for Aeroderivative Gas Turbine Engines", Journal of Engineering for Gas Turbines and Power, vol. 118:1,pp 38-45, 1996.

[5]. Dowling A.P., Hubbard S., "Instability in lean premixed combustors", Proc. Instn. Mech., Part A: 214, p 317, 2000.

[6]. Venkataraman K.K., Preston L.H., Simons D.W., Lee B.J., Lee J.G., Santavicca D.A., "Mechanism of Combustion Instability in a Lean Premixed Dump Combustor", Journal and Propulsion and Power, vol. 15:6, p 909, 1999.

[7]. Rayleigh J.W.S., "The Theory of Sound", Macmillan, New York, 1945.

[8]. Lieuwen T.C. and Yang V., "Combustion Instabilities in Gas Turbine Engines", Progress in Astronautics and Aeronautics vol. 210, p 505, 2005.

[9]. Allouis C., Beretta F., Amoresano A., "Experimental Study of Lean Premixed Prevaporized Combustion Fluctuations in a Gas Turbine Burner", Combustion Science and Technology, vol.180, pp 900-909, 2008.

[10]. Allouis C., Pagliara R., Saponaro A., "Fast infrared imaging for combustion stability analysis of industrial burners", Experimental Thermal and Fluid Science, vol. 43, pp. 2-8, 2012. 
[11].Price R. B., Hurle I. R. and Sudgen, T. M., "Optical studies on generation of noise in turbulent flames", Twelfth Symposium on Combustion, The Combustion Institute, Pittsburgh, pp. 1093-1102, 1969.

[12].Keller, J. O. and Saito, K., "Measurement of the combustion flow in a pulsed combustor", Combustion Science and Technology, vol. 53, pp 137-163, 1987.

[13]. Candel S., Durox D., Schuller T., Darabiha N., Hakim L., Schmitt T., "Advances in combustion and propulsion applications", European Journal of Mechanics - B/Fluids, vol. 40, pp. 87-106, 2013.

[14].Blevins, L. G.; Renfro, M. W.; Lyle, K. H.; Laurendeau, N. M.; Gore, J. P., "Experimental Study of Temperature and $\mathrm{CH}$ Radical Location in Partially Premixed CH4/Air Coflow Flames", Combustion and Flame, Vol. 118, No. 4, pp. 684-696, 1999. 